\title{
A HYBRID GENETIC-LINEAR ALGORITHM FOR 2D INVERSION OF SETS OF VERTICAL ELECTRICAL SOUNDING
}

\author{
Niraldo R. Ferreira, ${ }^{1}$ Milton José Porsani, ${ }^{2}$ Saulo Pomponet de Oliveira ${ }^{3}$ \\ Recebido em 23 out. 2003 / Aceito em 6 may, 2004 \\ Received oct. 23, 2003 / Accepted may 6, 2004
}

\begin{abstract}
The inversion of vertical electrical sounding (VES) is normally performed considering a stratified medium formed by homogeneous, isotropic and horizontal layers. The simplicity of this geophysical model makes the inversion simple and computationally fast, and together with the main characteristics of the electroresistivity method, it was greatly responsible to make VES one of the most popular geophysical method for groundwater exploration and engineering geophysics. However, even in a sedimentary basin where the geology is more conform, the assumption of horizontal and homogeneous layers is not necessarily valid, limiting the reliability of the inversion results.

In this paper we present a fast and robust $2 \mathrm{D}$ resistivity modeling and inversion algorithm for the interpretation of sets of VES. We consider three inversion algorithms: the Gauss-Newton method of linearized inversion (LI), the genetic algorithm (GA), and a hybrid approach (GA-LI) that uses LI to improve the best model at the end of each step of the GA. The medium parametrization consists of the partition of the domain into fixed homogeneous rectangular blocks such that their resistivities are the only free parameters. The apparent resistivity is evaluated by an iterative scheme that is derived from a finite-difference discretization of the potential differential equation. We enhance the convergence rate of the scheme by adopting an incomplete Cholesky preconditioner.

Numerical results using synthetic and real $2 D$ apparent resistivity data formed by sets of VES for the Schlumberger configuration illustrate the performance of the hybrid GA-LI algorithm. The VES field data were acquired near Conceição do Coité, state of Bahia, Brazil. We compare the performance of the LI, GA and GA-LI algorithms.
\end{abstract}

Keywords: Incomplete Cholesky, $2 D$ resistivity modeling, geophysical inversion, genetic algorithms, linearized inversion, hybrid optimization.

\section{RESUMO}

A inversão de uma sondagem elétrica vertical (SEV) normalmente assume que o meio é estratifcado e formado por camadas horizontais homogêneas e isotrópicas. A simplicidade deste modelo geofísico torna a inversão simples e com reduzido custo computacional. Esta simplicidade, junto às principais qualidades do método de eletroresistividade, foi responsável por tornar a SEV um dos métodos geofísicos mais populares nos trabalhos de exploração de águas subterrâneas e geofísica aplicada à engenharia. Porém, mesmo em bacias sedimentares, onde a geologia é mais conforme, a hipótese de camadas planas e homogêneas não é válida, 0 que limita a confiabilidade dos resultados da inversão.

Apresentamos neste artigo um algoritmo rápido e robusto de modelagem e inversão eletroresistiva para a interpretação de conjuntos de SEVs. Consideramos três algoritmos de inversão: 0 método de inversão linearizada de Gauss-Newton (LI), o algorítmo genético (GA), e uma abordagem híbrida (GA-LI) que usa a inversão linearizada para aprimorar o melhor modelo obtido ao final de cada geração do algoritmo genético. A parametrização do meio consiste na partição do dommínio em blocos retangulares e homogêneos, de modo que a resistividade de cada bloco é um parâmetro do modelo. A resistividade aparente é calculada com um método iterativo baseado numa aproximação por diferenças finitas da equação do potencial elétrico. Um precondicionamento do tipo Cholesky incompleto é utilizado para acelerar a convergência do método.

Avaliamos a performance do método híbrido por meio de experimentos numéricos com perfis de eletroresistividades reais e sintéticos, formados por conjuntos de SEVs obtidas com o arranjo Schlumberger. Os dados de campo foram coletados nas proximidades de Conceição do Coité, estado da Bahia, Brasil.

Palavras-chave: fatoração incompleta de Cholesky, modelagem bidimensional de resistividade, inversão geofísica, algoritmos genéticos, inversão linearizada, otimização híbrida.

1 Escola Politécnica - Universidade Federal da Bahia -Rua Prof. Aristides Novis, 02 - Federação - CEP: 40210-730 Salvador- BA - E-mail: niraldo@ufba.br

2 Centro de Pesquisa em Geofísica e Geologia - Instituto de Geociências - Universidade Federal da Bahia - Rua Caetano Moura, 123 sala 312 - C - Campus Universitário de Ondina - Salvador - BA - CEP: 40170-115 - Telefax: (71) 203-8551 - E-mail: porsani@cppg.ufba.br

3 Centro de Pesquisa em Geofísica e Geologia - Instituto de Geociências - Universidade Federal da Bahia - Rua Caetano Moura, 123 sala 312 - C - Campus Universitário de Ondina - Salvador - BA - CEP: 40170-115 - Telefax: (71) 203-8551 -E-mail: saulopo@cppg.ufba.br 


\section{INTRODUCTION}

Inversion of resistivity sounding is a non-linear problem that estimates the spatial distribution of resistivities of the subsoil materials from apparent resistivity data measurements. Local and global optimization algorithms have been reported in geophysical data inversion by many authors (TARANTOLA; VALETTE, 1982; ROTHMAN, 1985; SEN; BHATTACHARYA; STOFFA, 1993; CHUNDURU et al., 1997). In case we begin the inversion using a starting model located near to a local or a global minimum, gradient methods can be very useful to find an optimal solution. Otherwise, global optimization algorithms such as simulated annealing or genetic algorithms can be used. The major drawbacks associated with local and global algorithms are the requirement for a prioriinformation and the computational cost, respectively. Several different hybrid optimization approaches can be proposed to overcome these drawbacks (CHUNDURU et al., 1997; PORSANI et al., 2000).

To develop an efficient hybrid optimization scheme, it is important to choose efficient global and local algorithms. For geophysical inversion, successful attempts were made by several authors (CARY; CHAPMAN, 1988; PORSANI et al., 1993; LIU; HARTZELL; STEPHENSON, 1995). A very good explanation about the advantages and drawbacks of local, global and hybrid algorithms was presented by Chunduru and others (1997). Also to develop an efficient hybrid inversion algorithm for $2 D$ resistivity inversion, a fast forward modeling algorithm is required. For the $2 \mathrm{D}$ inversion of field resistivity sounding data we have implemented a 2D finite-difference algorithm for computation of the forward modeling that uses an incomplete Cholesky factorization scheme (MEIJERINK; VAN DER VORST, 1977) coupled with the preconditioned conjugate gradient method (GREENBAUM, 1997).

Electrical resistivity inversion methods aim to determine the distribution of subsurface resistivity by measuring the distribution of electrical potential from a set of current electrodes at the earth surface. For a Schlumberger configuration of electrodes, the apparent resistivity satisfies the equation

$\rho_{a}=\pi\left(\frac{A B^{2}}{4 M N}-\frac{M N}{4}\right) \frac{\Delta \phi}{I}$,

where $\Delta \phi$ is the electrical potential difference between two electrodes located at $M$ and $N$, and $I$ is the current generated by two electrodes located at $A$ and $B$. The axis $x$ is set along the electrodes.

The one-dimensional method of Vertical Electrical Sounding (VES) for horizontally layered media is well known ${ }^{4}$. The free parameters of this model are the resistivity $\rho_{i}(1 \leq \imath \leq n)$ and the thickness $h_{i}(1 \leq i \leq n)$ of each layer, and are represented by the vector $\mathbf{m}$. The center of electrode configuration is fixed, and the spacing $s=A B / 2$ is the only independent variable. One can evaluate the apparent resistivity $\rho_{a}(\mathbf{m}, s)$ in closed form (KOEFOED, 1979).

The two-dimensional model accounts for both lateral and vertical variations of resistivity. In this case, the apparent resistivity $r_{a}$ also depends on the position $x$ where the VES is performed. We partition the domain into $N$ rectangular blocks. The components of the free parameter vector $\mathbf{m}$ are the resistivity of each block. Unlike the $1 \mathrm{D}$ model, the apparent resistivities $\rho_{a}\left(\mathbf{m}, x, s_{i}\right)$ are approximated by a numerical method. We employ a finite-difference method to evaluate the scalar electrical potential $\phi$, as described in the following section.

\section{FINITE-DIFFERENCE MODELING}

Assuming that the electric conductivity $\sigma$ of the medium varies only along the axis $x$ and the depth $z$, the electrical potential generated by a pointwise source at $\left(x_{f}, 0,0\right)$ is a solution of the Poisson equation

$-\nabla \cdot[\sigma(x, z) \nabla \phi(x, y, z)]=I \delta\left(x-x_{f}\right) \delta(y) \delta(z)$,

where $\delta(\cdot)$ is the Dirac delta and $\nabla$ is the gradient vector operator. A Fourier transform in the $y$ direction yields

$-\nabla \cdot\left[\sigma(x, z) \nabla \tilde{\phi}_{k}(x, z)\right]+k^{2} \sigma(x, z)$

$\tilde{\phi}_{k}(x, z)=\frac{I}{2} \delta\left(x-x_{f}\right) \delta(z)$,

$\tilde{\phi}_{k}(x, z)=\int_{0}^{\infty} \phi(x, y, z) \cos (k y) d y$,

$\phi(x, y, z)=\frac{2}{\pi} \int_{0}^{\infty} \tilde{\phi}_{k}(x, z) \cos (k y) \mathrm{dk}$.

Equation (3) is discretized using an $N \mathrm{x} M$ non-uniform rectangular grid. We evaluate the finite-difference solution $\tilde{\phi}_{i, j} \approx \tilde{\phi}_{k}\left(x_{i}, z_{j}\right)$ in its interior domain of validity according to Dey and Morrison (1979):

$C_{l}^{i, j} \tilde{\phi}_{i-1, j}+C_{r}^{i, j} \tilde{\phi}_{i+1, j}+C_{u}^{i, j} \tilde{\phi}_{i, j-1}+$

$+C_{d}^{i, j} \tilde{\phi}_{i, j+1}+C_{c}^{i, j} \tilde{\phi}_{i, j}=b_{i j}$,

$b_{i j}=\left\{\begin{array}{ll}\frac{I}{2} & ,(i, j)=\left(i_{f}, 1\right) \\ 0 & ,(i, j) \neq\left(i_{f}, 1\right)\end{array}\right.$, 


$$
\begin{aligned}
C_{l}^{i, j}= & \frac{-1}{2\left(x_{i}-x_{i-1}\right)}\left[\sigma_{i-1, j-1}\left(z_{j}-z_{j-1}\right)+\sigma_{i-1, j}\left(z_{j+1}-z_{j}\right)\right], \\
C_{r}^{i, j}= & \frac{-1}{2\left(x_{i+1}-x_{i}\right)}\left[\sigma_{i-1, j-1}\left(z_{j}-z_{j-1}\right)+\sigma_{i, j}\left(z_{j+1}-z_{j}\right)\right], \\
C_{u}^{i, j}= & \frac{-1}{2\left(z_{j}-z_{j-1}\right)}\left[\sigma_{i-1, j-1}\left(x_{i}-x_{i-1}\right)+\sigma_{i, j-1}\left(x_{i+1}-x_{i}\right)\right], \quad(8) \\
C_{d}^{i, j}= & \frac{-1}{2\left(z_{j+1}-z_{j}\right)}\left[\sigma_{i-1, j}\left(x_{i}-x_{i-1}\right)+\sigma_{i, j}\left(x_{i+1}-x_{i}\right)\right], \\
C_{c}^{i, j}= & -\left[C_{l}^{i, j}+C_{r}^{i, j}+C_{u}^{i, j}+C_{d}^{i, j}-k^{2} A_{i, j}\right], \\
A_{i, j}= & \frac{1}{4}\left[\sigma_{i-1, j-1}\left(x_{i}-x_{i-1}\right)\left(z_{j}-z_{j-1}\right)+\sigma_{i, j-1}\left(x_{i+1}-x_{i}\right)\left(z_{j}-z_{j-1}\right)\right. \\
& \left.+\sigma_{i, j}\left(x_{i+1}-x_{i}\right)\left(z_{j+1}-z_{j}\right)+\sigma_{i-1, j}\left(x_{i}-x_{i-1}\right)\left(z_{j+1}-z_{j}\right)\right] .
\end{aligned}
$$

The boundary condition at the top layer is

$$
\sigma_{i, 1} \frac{\partial \tilde{\phi}_{i, j}}{\partial n}=0 \text {. }
$$

We stretch the grid in geometric progression near the lateral and lower boundaries, imposing the following condition (DEY; MORRISON, 1979):

$$
\frac{\partial \tilde{\phi}(x, k, z)}{\partial n}+k \frac{K_{1}(k r)}{K_{0}(k r)} \tilde{\phi}(x, k, z)=0, \quad r^{2}=x^{2}+z^{2},
$$

where $K_{0,1}$ are the modified Bessel functions (ABRAMOWITZ; STEGUN, 1970). We employed growth factors of 2.529 and 2.215 in the horizontal and vertical directions, respectively (MEDEIROS, 1987).

Let $\mathbf{x}=\left(\tilde{\phi}_{11}, \ldots, \tilde{\phi}_{1 N}, \tilde{\phi}_{21}, \ldots, \tilde{\phi}_{M N}\right)^{T}$ and $\mathbf{b}=\left(b_{11}, \ldots b_{M N}\right)^{T}$. Equations (6)-(10) yield a linear system of the form $\mathbf{C x}=\mathbf{b}$. The capacitance matrix $\mathbf{C}$ is symmetric, positive definite, and satisfies $\mathrm{C}_{i, j}=0$ if $|i-j| \neq 0,1, M$.

The Cholesky factorization $\mathbf{C}=\mathbf{L L}^{\top}$ leads to a lower triangular matrix $\mathrm{L}$ such that $L_{i, j} \neq 0$ if $|i-j| \leq M$ in general. However, the observed values of $\left|L_{i, j}\right|$ are relatively small if $|i-j| \neq 0,1, M$. For instance, Figure 1 displays the absolute values of the diagonals of $\mathbf{L}$ resulting from the model with $M=10, N=20$, and a medium composed of two homogeneous layers with the same thickness. The resistivities of the upper and lower layers are $\rho_{1}=10 \Omega m$ and $\rho_{2}=500 \Omega m$, respectively.

We consider an incomplete Cholesky factorization $\mathbf{C} » \mathbf{H H}^{T}$ where $\mathbf{H}$ is a lower triangular matrix satisfying $H_{i, j}=0$ if $i-j \neq 0,1, M$. Since $\mathbf{H}$ preserves the sparsity pattern of $\mathbf{C}$, the matrix $\mathbf{H H}^{T}$ is a suitable preconditioner for iterative methods for solving $\mathbf{C x}=\mathbf{b}$ (MEIJERINK; VAN DER VORST, 1977).
Once $\tilde{\phi}_{k}\left(x_{i}, z_{j}\right)$ is approximated, the electrical potential $\phi\left(x_{i}, 0, z_{j}\right)$ is estimated by numerically integrating Equation (5) according to Dey and Morrison (1979). We employ the following frequency values: $k=0.001,0.002,0.004,0.008,0.015,0.03,0.06$, $0.09,0.12,0.15 \mathrm{~m}^{-1}$. To evaluate the apparent resistivity, we place the potential electrodes at the surface nodes of the grid, so that the difference of electrical potential needed in (1) can be computed from $\phi\left(x_{i}, 0,0\right)(1 \leq i \leq M)$ and a prescribed spacing $s$.

\section{A Preconditioned Conjugated Gradient Algorithm}

The incomplete Cholesky factorization approximates the solution $\mathbf{x}$ of $\mathbf{C} \mathbf{x}=\mathbf{b}$ by the solution $\mathbf{x}_{\mathbf{0}}$ of $\mathbf{H}^{\top} \mathbf{x}_{\mathbf{0}^{\prime}}$ where $\mathbf{H y}=\mathbf{b}$. To further improve this estimate solution we employ the preconditioned conjugated gradient (PCG) method (GREENBAUM, 1997). In the following algorithm, $n_{\text {iter }}$ is the maximum number of iterations, $\left\|\mathbf{r}_{l}\right\|=\left(\mathbf{r}_{l}^{T} \mathbf{r}_{l}\right)^{1 / 2}$, and $t o l$ is the error tolerance.

\section{Steps of the preconditioned conjugated gradient algorithm}

- calculate $\mathbf{r}_{\mathbf{0}}=\mathbf{b}-\mathbf{C} \mathbf{x}_{\mathbf{0}}$;

- solve $\mathbf{H}^{\mathrm{T}} \mathbf{z}_{\mathbf{0}}=\mathbf{y}$ for $\mathbf{z}_{0^{\prime}}$ where $\mathbf{H y}=\mathbf{r}_{\mathbf{0}^{\prime}}$ and set $\mathbf{p}_{\mathbf{0}}=\mathbf{z}_{\mathbf{0}}$;

- for $l=0,1, \ldots, n_{\text {iter }}\left(\left\|\mathbf{r}_{l}\right\| \geq t o l\right)$

- calculate $x_{l+1}=\mathbf{x}_{l}+\alpha_{l} \mathbf{p}_{l}$, where $\alpha_{l}=\frac{\mathbf{r}_{l}^{T} \mathbf{z}_{l}}{\mathbf{p}_{l}^{T} \mathbf{C}_{\mathbf{P} l}}$;

- calculate $\mathbf{r}_{l+1}=\mathbf{r}_{l}-\alpha_{l} \mathbf{C}_{\mathbf{P} l}$;

- solve $\mathbf{H}^{T} \mathbf{z}_{l+1}=\mathbf{y}$ for $\mathbf{z}_{l+1}$, where $\mathbf{H y}=\mathbf{r}_{l+1}$;

- calculate $\mathbf{p}_{l+1}=\mathbf{z}_{l+1}+\beta_{l \mathbf{p} l}$, where $\beta_{l}=\frac{\mathbf{r}_{l+1}^{T} \mathbf{z}_{l+1}}{\mathbf{r}_{l}^{T} \mathbf{z}_{l}}$;

A similar algorithm has been used in 3D electroresistivity modeling (ZHANG; MACKIE; MADDEN, 1995). Figure 2 compares the CPU processing time of the PCG method above and a direct method based on the Cholesky factorization (CF). The computations were performed in a RISC 6000 IBM and the model problem is the same as in Figure 1, with $N=$ 100 and $M=5,10, \ldots, 40$. We set a tolerance, to $l=10^{-10}$, for the PCG method. In this example the PCG algorithm becomes a better alternative when $N \times M$ is greater than 4000 , which is a suitable resolution for two-dimensional inversion of real data. 


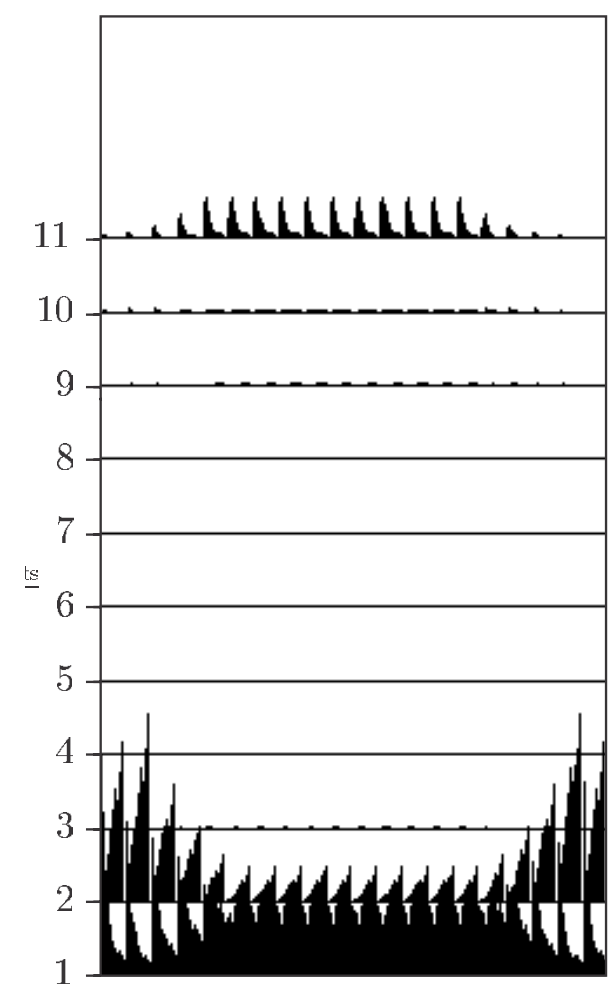

Figure 1 - Absolute values of diagonal $(k=1)$ and off-diagonal $(k>1)$ components of the matrix $L$.

Figura 1 - Valores absolutos dos componentes da matriz L, ao longo da diagonal $(k=1)$ e fora da diagonal $(k>1)$.

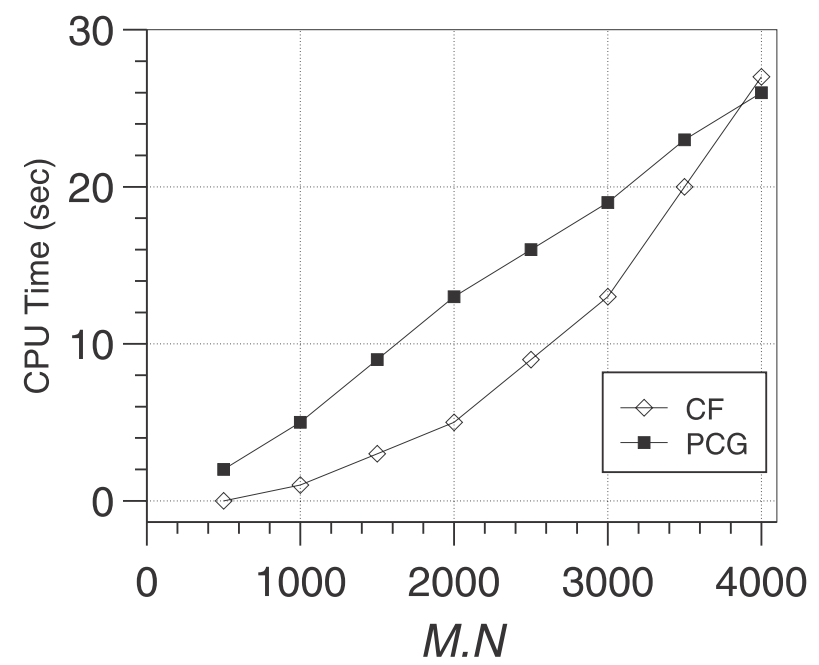

Figure 2 - Comparison of CPU times of Cholesky factorization (CF) and preconditioned conjugate gradient (PCG) methods. Figura 2 - Comparação do tempo de (PU da fatoração de Cholesky (FC) e do método de gradientes conjugados precondicionado (GCP). 


\section{LINEARIZED INVERSION}

Let $1 \leq p \leq 2$. The $L_{p}$ norm of an $M$-dimensional vector $\mathbf{v}=\left(v_{1}, \ldots v_{N}\right)^{T}$ is given by $\|\mathbf{v}\|_{p}=\left(\sum_{i=1}^{M}\left|v_{i}\right|^{p}\right)^{\frac{1}{p}}$.

Let us introduce an iterative scheme to minimize the objective function proposed by Scales and Gersztenkorn (1986):

$E(\mathbf{m})=\sum_{i=1}^{M}\left|\rho_{a}\left(x_{i}, s_{i}\right)-\rho_{a}\left(\mathbf{m}, x_{i}, s_{i}\right)\right|^{p}$,

where $\rho_{a}\left(x_{i}, s_{i}\right)$ and $\rho_{a}\left(\mathbf{m}, x_{i}, s_{i}\right)$ are the observed and theoretical apparent resistivities, respectively. Note that $E(\mathbf{m})$ is the $L_{p}$ norm of the error of the theoretical apparent resistivities to the power $p$. We linearize $\rho_{a}\left(\mathbf{m}, x_{i}, s_{i}\right)$ by Taylor's series about an estimate free parameter vector $\mathbf{m}_{\boldsymbol{k}}$ :

$\rho_{a}\left(\mathbf{m}, x_{i}, s_{i}\right) \approx \tilde{\rho}_{a}\left(\mathbf{m}, x_{i}, s_{i}\right)=$

$=\rho_{a}\left(\mathbf{m}_{k}, x_{i}, s_{i}\right)+\frac{\partial_{\rho a}\left(\mathbf{m}_{k}, x_{i}, s_{i}\right)}{\partial \mathbf{m}}\left(\mathbf{m}-\mathbf{m}_{k}\right)$.

Let $\quad d_{k, i}=\rho_{a}\left(x_{i}, s_{i}\right)-\rho_{a}\left(\mathbf{m}_{k}, x_{i}, s_{i}\right), r_{k, i}=$ $=\left|\rho_{a}\left(x_{i}, s_{i}\right)-\tilde{\rho}_{a}\left(\mathbf{m}, x_{i}, s_{i}\right)\right|^{p-2}(1 \leq i \leq M)$, and

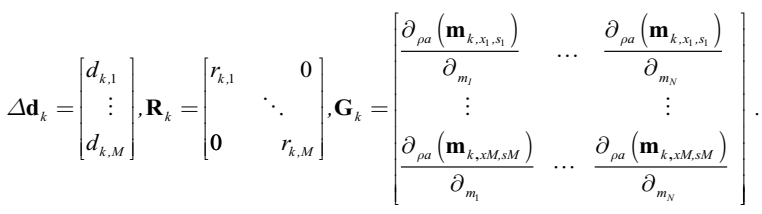

Substituting (12) into (11), we find a quadratic function of $\mathbf{m}$, whose minimum satisfies

$\left(G_{k}^{T} R_{k} G_{k}\right) \Delta m=G_{k}^{T} R_{k} \Delta d_{k}$.

Where $\Delta \mathbf{m}=\left(\mathbf{m}_{k+1}-\mathbf{m}_{k}\right)$. By using a regularization factor $\lambda$ (MENKE, 1989) we compute the new solution $\mathbf{m}_{k+1}$ as

$m_{k+1}=m_{k}+\left(G_{k}^{T} R_{k} G_{k}+» I\right)^{-1} G_{k}^{T} R_{k} \Delta d_{k}$.

In particular, the method with $p=2$ and $\lambda=0$ corresponds to the plain least squares method. The row $i$ of the sensitivity matrix $\mathbf{G}_{k}$ is weighted by the $i$-th diagonal component of the matrix $\mathbf{R}_{k^{\prime}}$ which is a function of the deviation between the observed resistivity values, and the ones computed from current model $\mathbf{m}_{k}$ (PORSANI; NIWAS; FERREIRA, 2001).

To increase the robustness of the algorithm, we apply a logarithmic scaling to the free parameters and to the field data (RIJO et al., 1977). Moreover, given a tolerance parameter $\varepsilon$, we set $r_{k, i}=\varepsilon^{p-2}$ if $\left|\rho_{a}\left(x_{i}, s_{i}\right)-\tilde{\rho}_{a}\left(\mathbf{m}, x_{i}, s_{i}\right)\right| \leq \varepsilon$.

We employ a harmonic measure of fitness (PORSANI et al., 2000)

$\Phi\left(\mathbf{m}_{k}\right)=\frac{2 \sum_{i=1}^{M}\left[\rho_{a}\left(x_{i}, s_{i}\right) \rho_{a}\left(\mathbf{m}_{k}, x_{i}, s_{i}\right)\right]}{\sum_{i=1}^{M}\left[\rho_{a}\left(\mathbf{m}_{k}, x_{i}, s_{i}\right)^{2}+\rho_{a}\left(x_{i}, s_{i}\right)^{2}\right]}$.

The ratio $\Phi$ varies within $[-1,1]$, and approaches 1 as $\rho_{a}\left(\mathbf{m}_{k}, x_{i}, s_{i}\right)$ approaches $\rho_{a}\left(x_{i}, s_{i}\right)(1 \leq i \leq M)$. The components of the sensitivity matrix are approximated by forward differences (MCGILIVRAY; OLDENBURG, 1990). We employ a conjugated gradient method to evaluate $\mathbf{m}_{k+1}$ from (14). Let $\mathbf{A}=\mathbf{G}_{k}^{T} \mathbf{R}_{k} \mathbf{G}_{k}+\lambda \mathbf{I}$. We have that:

$p_{l}^{T} A p_{l}=p_{l}^{T} G_{k}^{T} R_{k} G_{k} p_{l}+\lambda p_{l}^{T} p_{l}=$ $=q_{l}^{T} R_{k} p_{l}+\lambda p_{l}^{T} p_{l}, \quad q_{l}=G_{k} q_{l}$

which motivates modifying the conjugated gradient algorithm to avoid the computation of $\mathbf{G}_{k}^{T} \mathbf{R}_{k} \mathbf{G}_{k}$ :

\section{Steps of the conjugated gradient algorithm for $L_{p}$ inversion}

- $s_{0}=\Delta d_{k}-G_{k} x_{0}$;

- $\mathbf{r}_{0}=\mathbf{G}_{k}^{T} \mathbf{R}_{k} s_{0}-» x_{0}$;

- $p_{0}=r_{0}$ and $\mathbf{q}_{0} \mathbf{G}_{k} p_{0}$;

- for $l=0,1, \ldots, n_{\text {iter }}\left(\left\|r_{l}\right\| \geq t o l\right)$.

- $x_{l+1}=x_{l}+\alpha_{l} \mathbf{p}_{l}$, where $\alpha_{l}=\frac{r_{l}^{T} r_{l}}{\mathbf{q}_{l}^{T} \mathbf{R}_{k} \mathbf{q}_{l}+\lambda \mathbf{p}_{l}^{T} \mathbf{p}_{l}} ;$

$-\mathbf{s}_{l+1}=\mathbf{s}_{l}-\alpha_{l} \mathbf{q}_{l}$

- $\mathbf{r}_{l+1} \mathbf{G}_{k}^{T} \mathbf{R}_{k} \mathbf{s}_{l+1}-\lambda \mathbf{x}_{l+1} ;$

- $\mathbf{p}_{l+1}=\mathbf{r}_{l+1}+\beta_{l} \mathbf{p}_{l}$, where $\beta_{l} \frac{\mathbf{r}_{l+1}^{T} \mathbf{r}_{l+1}}{\mathbf{r}_{l+l}^{T} \mathbf{r}_{l}}$;

- $\mathbf{q}_{k}=\mathbf{G}_{k} \mathbf{p}_{k}$ 
When $\lambda=0$, the algorithm designed by Gersztenkorn, Bednard e Lines (1986) for $1 \mathrm{D}$ inversion of the acoustic wave equation is recovered.

\section{NUMERICAL EXAMPLES}

\section{Inversion of synthetic data}

We consider the model of a buried dike outlined in Figure 3. The vertical electrical soundings are performed throughout 21 stations with a set of $19 s$-values. Noise is introduced when $A B / 2=17.5 \mathrm{~m}$, $47.5 \mathrm{~m}, 87.5 \mathrm{~m}$ and $107.5 \mathrm{~m}$.

The horizontal grid employs 252 nodes. Five nodes are distributed in geometric progression on both ends, while the increment between interior nodes is $5 \mathrm{~m}$. The vertical grid employs 26 nodes with non-uniform spacing.

In the experiment it is assumed that the location and size of the blocks are known. The initial solution 2 is $\mathbf{m}_{0}=\rho(1,1,1,1)^{T}$, $\rho=500 \Omega m$. Figure 4 compares the performance of inversions in the norms $L_{1}$ and $L_{2}$ without regularization $(\lambda=0)$.

Figure 5 shows three VES corresponding to stations 1,7 and 11 , inverted using $L_{1}$ and $L_{2}$ norms. We compare results of apparent resistivities resulting from two extreme scenarios: when the dike width is zero $\left(\rho_{0}\right)$ and when the width is infinite $\left(\rho_{\infty}\right)$. These scenarios yield horizontally layered media, and can be considered as lower and upper bounds of the influence of the dike; that is, $\rho_{0}$ does not take the dike into account, while $\rho_{\infty}$ is driven by the resistivity of the dike and the upper layer (FERREIRA, 1999).

Both inversions delivered exact block resistivities when outlier noise is removed (note that $\Phi\left(\mathbf{m}_{10}\right)=1$ ). Otherwise, the resistivities were accurately computed in the $L_{1}$ norm (Table 1).

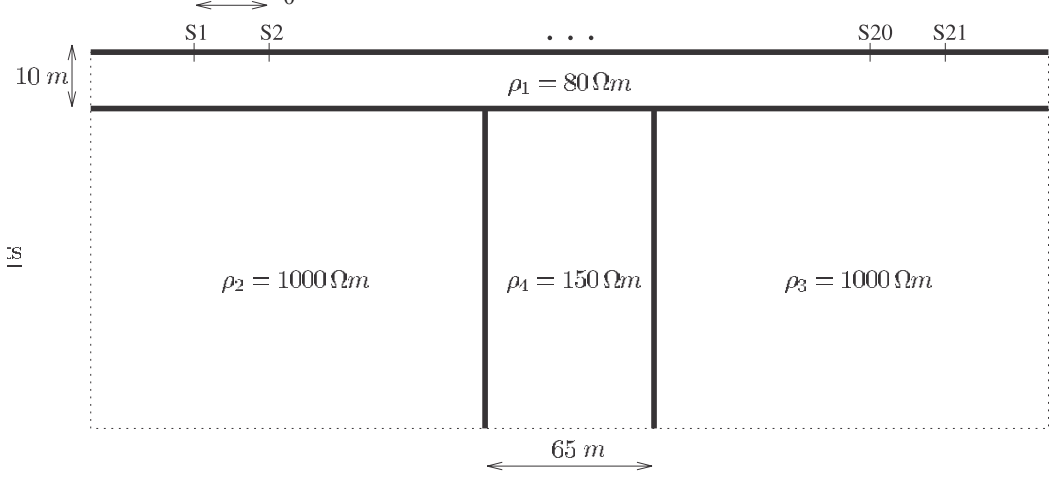

Figure 3 - 2-D model represented by a vertical dike of resistivity value of $150 \Omega$ m intruded in a medium of $1000 \Omega m$, and covered by a layer of resistivity value of $80 \Omega \mathrm{m}$.

Figura 3 - Modelo bidimensional de um dique vertical com resistividade de $150 \Omega$ m incrustado em um meio de $1000 \Omega m$, e coberto por uma camada com $80 \Omega m$ de resistividade.
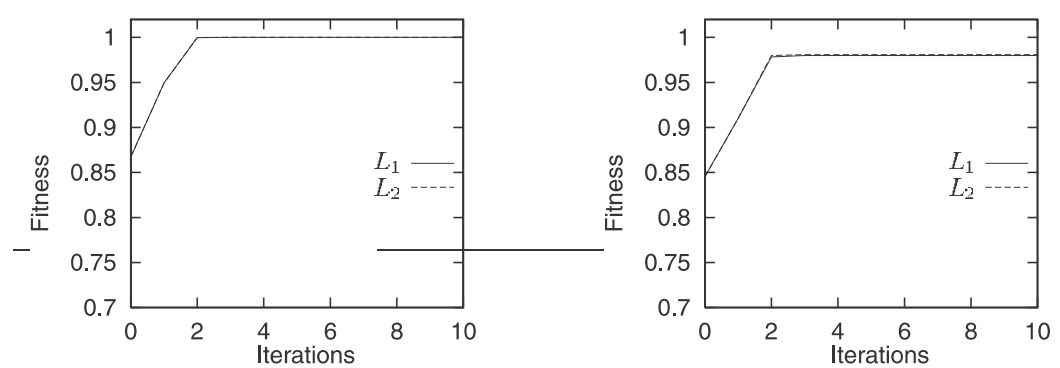

Figure 4 - Performance of linearized inversion algorithms on synthetic data according to equation (15) in both $L_{1}$ and $L_{2}$ norms. The results on the left employed the exact data, while the ones on the right employed data perturbed with outlier noise. Figura 4 - Performance dos algoritmos de inversão linearizada de dados sintéticos, medida de acordo com a equação (15), nas normas $L_{1}$ e $L_{2}$. Os resultados à esquerda utilizaram parâmetros exatos, enquanto nos resultados à direita os parâmetros foram perturbados com ruído localizado. 
Table 1 - Results of linear inversion of resistivity considering synthetic data with outlier noise.

Tabela 1 -Resultados da inversão linear de resistividade considerando dados sintéticos com ruído localizado.

\begin{tabular}{|c|c|c|c|}
\hline $\mathrm{m}$ & exact & $L_{1}$ norm & $L_{2}$ norm \\
\hline$\rho_{1}(\Omega m)$ & 80.0 & 80.0 & 73.1 \\
\hline$\rho_{2}(\Omega m)$ & 1000.0 & 1000.0 & 1056.5 \\
\hline$\rho_{3}(\Omega m)$ & 1000.0 & 1000.0 & 1056.5 \\
\hline$\rho_{4}(\Omega m)$ & 150.0 & 150.0 & 183.8 \\
\hline
\end{tabular}
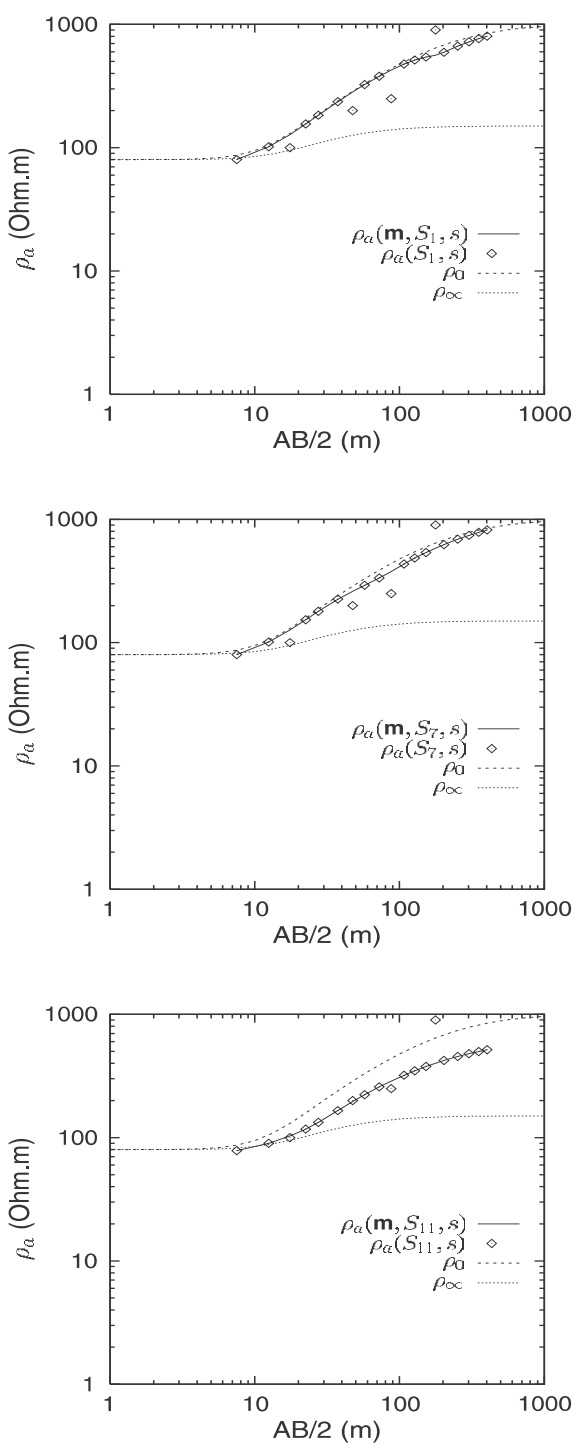

\section{Inversion of field data}

Our next experiment concerns field data acquired near Conceição do Coité, Brazil (PINHEIRO NETO, 2000). This area has an aquifer whose average yield is $1.78 \mathrm{~m}^{3} / \mathrm{h}$ with up to $7278 \mathrm{mg} / \mathrm{l}$ of total dissolved solids.

Twenty VES were acquired, and they are shown in Figure 6(a). In order to fit data to the finite-difference grid, we interpolated the VES curves to evaluate the apparent resistivity with an initial spacing $A B / 2=7.5 m$ and uniform increments of $5 m$.

The media parametrization is based on a partition into $27 \times 5$ blocks. We estimated the thickness of each layer by the average thick-

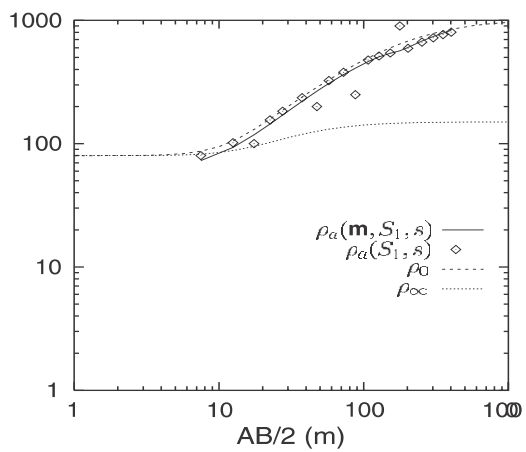

(a)

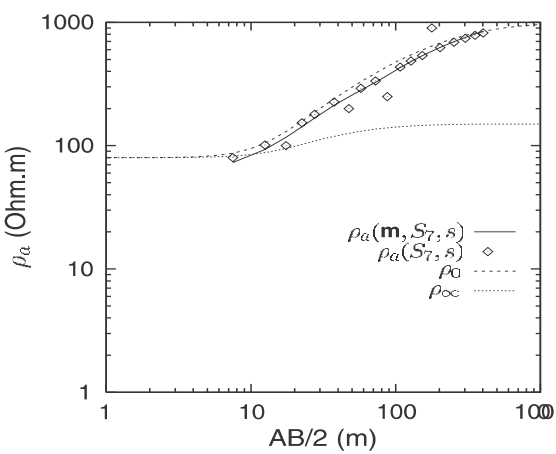

(b)

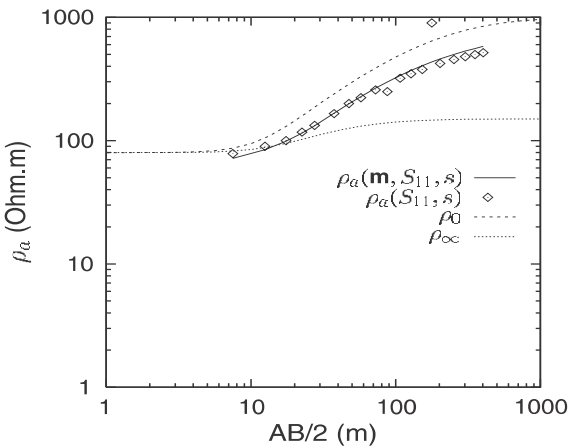

(c)

Figure 5 - VES on stations 1 (a), 7 (b), and 11 (c) obtained from the inverted models in the $L_{1}$ norm (left) and the $L_{2}$ norm (right). The theoretical apparent resistivity values when the dike width is zero $\left(\rho_{0}\right)$ or infinite $\left(\rho_{\infty}\right)$ are also shown.

Figura 5 - SEVs nas estações 7 (a), 7 (b), e 17 (c) obtidas dos modelos invertidos nas normas $L_{1}$ (esquerda) e $L_{2}$ (direita). Mostramos também os valores teóricos da resistividade aparente quando a largura do dique é zero $\left(\rho_{0}\right)$ ou infinita $\left(\rho_{\infty}\right)$. 
ness calculated at each station by using $1 D$ VES inversion. The initial model had $\rho=40 \Omega \mathrm{m}$ in the first four layers and $\rho=300 \Omega \mathrm{m}$ in the bottom layer. The horizontal grid was similar to the horizontal grid used in the synthetic model. We employed $302 \times 9$ nodes.

We performed 10 iterations of linearized inversion in the norms $L_{1}$ and $L_{2}$ with the same regularization factors $\lambda=0.001$ and $\lambda=0.1$ in the $L_{1}$ and $L_{2}$ norms, respectively. The percent relative errors with respect to the interpolated data were similar and under $45 \%$ as illustrated in Figure 7.

The region of low resistivity near station S5 of the computed models (Figure 6) is consistent with the presence of a water well near this station. The low resistivity between stations S14 and S16 is consistent with the evidence of salinization between stations S12 and S17.
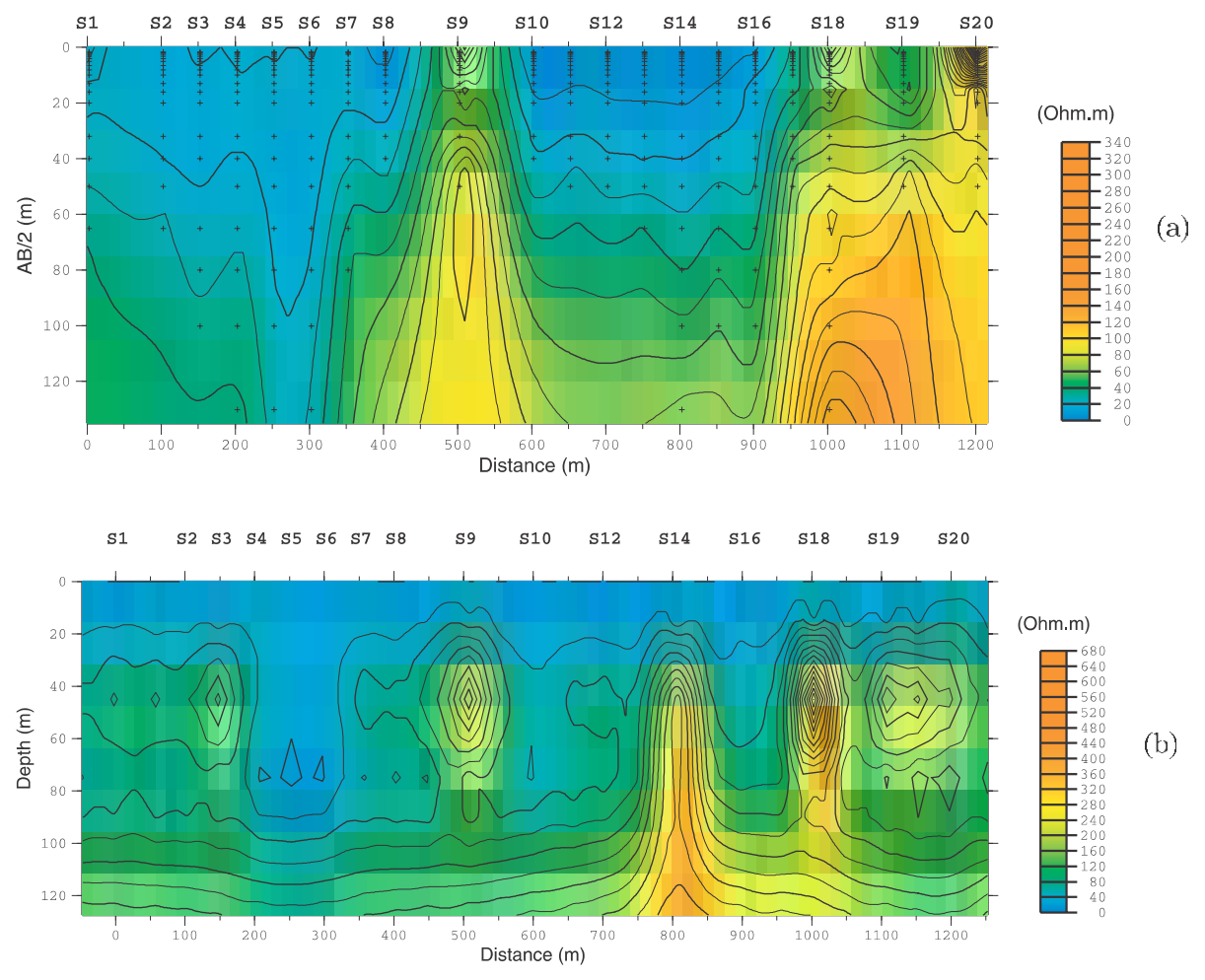

(b)

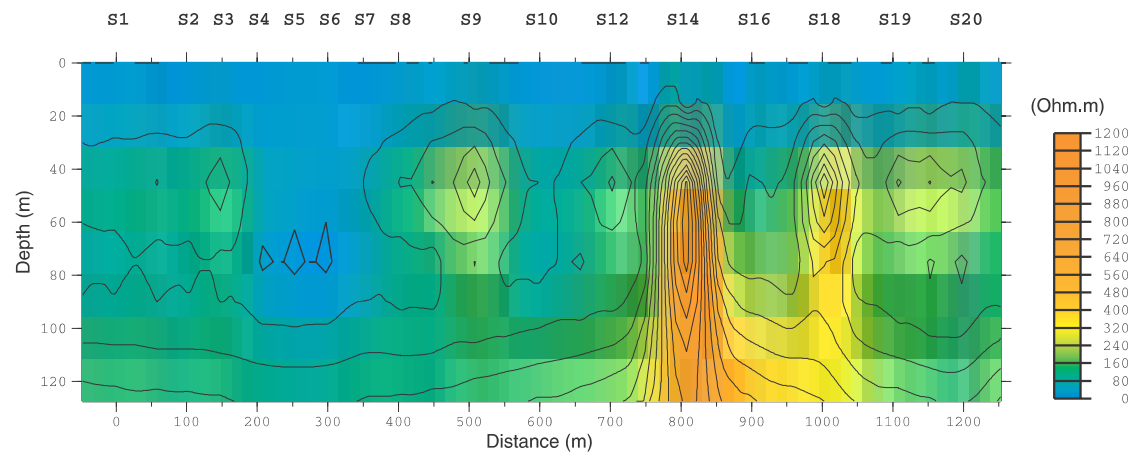

(c)

Figure 6 - Pseudo-section of apparent resistivity values generated by 20 unevenly spaced VES (a). The symbols $(+)$ below each VES indicate the $A B / 2$ position where the measurements were performed. Contours of the apparent resistivity values generated from linearized inversion in the $L_{1}$ norm (b) and $L_{2}$ norm (c).

Figura 6 - Pseudo-seção de valores de resistividade aparente gerados por 20 SEV s com espaçamento não-uniforme (a). Os símbolos (+) abaixo de cada SEV indicam a abertura AB/2 com que as medidas foram feitas. Pseudo-seção de valores de resistividade aparente gerados por inversão linearizada nas normas $L_{1}$ (b) e $L_{2}$ (c). 


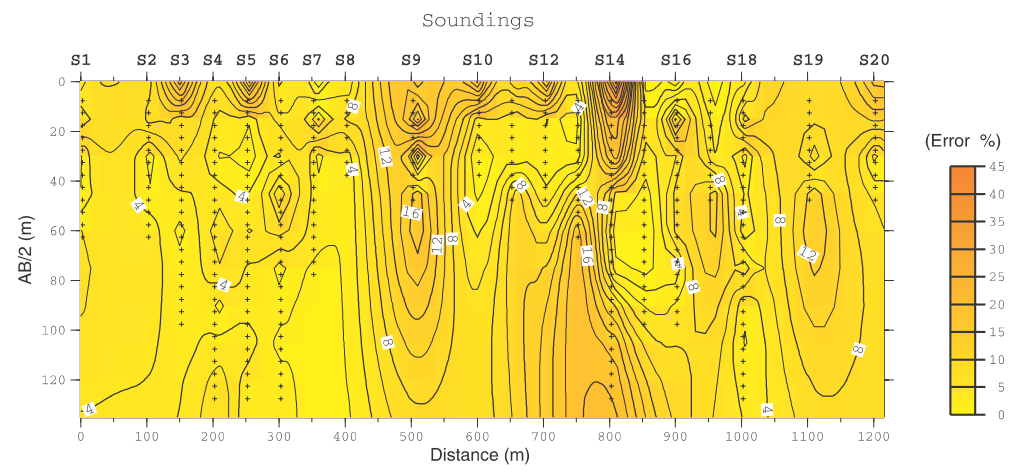

(a)

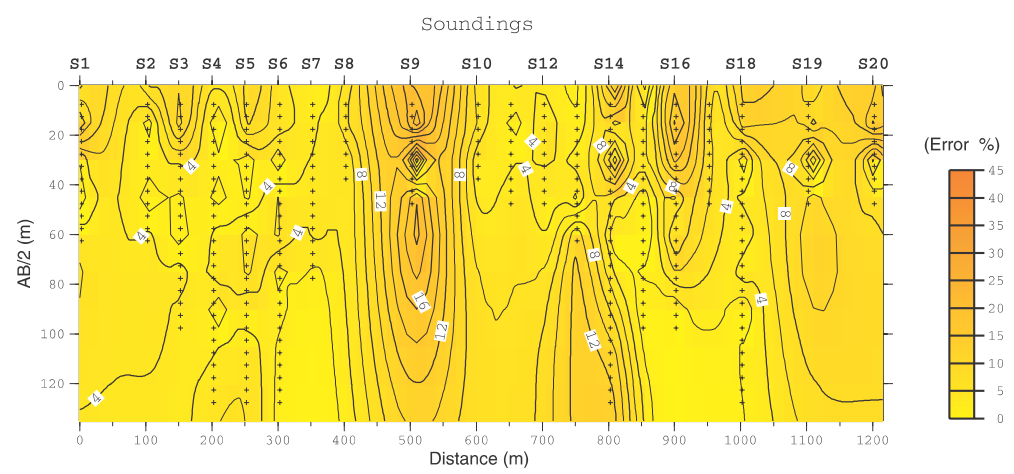

(b)

Figure 7 - Pseudo-section of percent relative error of the theoretical apparent resistivity values with respect to the observed apparent resistivity values for the linearized inversion algorithm in the $L_{1}$ norm (a) and the $L_{2}$ norm (b). Figura 7 - Pseudo-seção do erro relativo dos valores teóricos de resistividade aparente gerados por inversão linearizada nas normas $L_{1}$ (a) e $L_{2}$ (b) com respeito aos valores de resistividade aparente observados.

\section{GENETIC AND HYBRID ALGORITHMS}

Genetic algorithms $(G A)$ employ the concepts of survival of the fittest, crossover, and mutation to generate a set of free parameter vectors that progressively approach field data. These methods fit into the class of global, probabilistic optimization methods. Genetic algorithms are based on the principle of natural selection and genetics. Detailed descriptions of GA are given by Holland (1975) and Goldberg (1989), and theory and examples of geophysical applications can be found in Sen and Stoffa (1995). Basically, in the GA the model free parameters are coded in binary form. The algorithm starts with an ensemble of random models, and a new ensemble is generated similarly to the biological mechanism of reproduction that exists in nature. The models are chosen for reproduction with a probability proportional to their fitness value, and pairs of models are selected at random and exchange part of their binary chain. The crossover points are selected at random and all the bits to the right side are interchanged with a crossover probability, generating new models. To assure genetic variability in the population, a mutation process is adopted by changing at random a bit inside the binary chain based on a fixed probability. The new set of models are accepted with an update probability by comparing them with the models in the previous generation. The process of selection, crossover and mutation is applied until the fitness values converge, i.e., until the mean fitness approaches the highest fitness value in the population.

We start by randomly selecting a set (or population) of free parameter vectors $\mathbf{m}_{g, j}, 1 \leq j \leq P$, and $g=0$. We refer to each $\mathbf{m}_{g, j}$ 
as a model. In the second step, we evaluate the fitness $\Phi\left(\mathbf{m}_{g, j}\right)$ of each model according to equation (15). Then, we perform the following genetic operations.

- Selection: we select a limited number of models in pairs for reproduction. They are selected by a non-uniform probability function given by

$P_{s}\left(\mathbf{m}_{g, j}\right)=\frac{\exp \left[\Phi\left(\mathbf{m}_{g, j}\right) / T\right]}{\sum_{j=1}^{n} \exp \left[\Phi\left(\mathbf{m}_{g, j}\right) / T\right]}$,

where $T=T_{0} \gamma^{\beta}$ is associated with the temperature in the simulated annealing method. The temperature is used to de-emphasize the differences in the fitness values of the models in the initial generations and to exaggerate their differences at later generations (STOFFA; SEN, 1991).

- Crossover: each pair exchanges free parameter data with a fixed probability $P_{x}$ two new models are generated. Each component $m_{g j}^{y}(1 \leq i \leq M)$ of a model $\mathrm{m}_{g_{r i}}$ is restricted to a prescribed resolution; that is,

$m_{g j}^{i} \in\left\{m_{i, \min }, m_{i, \min +\Delta m_{i}}, \ldots, m_{i, \max }\right\}$

- Mutation: a random change with fixed probability $P_{m}$ may take place in each member of all pairs. Mutation helps to preserve the population diversity and leads to new search regions.
- Update: each new model $\mathbf{m}_{g}^{*}$ is compared with a randomly chosen current model $\mathbf{m}_{g, j}$. If $\Phi\left(\mathbf{m}_{g}^{*}\right)>\Phi\left(\mathbf{m}_{g, j}\right)$, then $\mathbf{m}_{g, j}$ is replaced by $\mathbf{m}_{g}^{*}$ according to a fixed probability $P_{u}$.

These steps create a new generation $\mathbf{m}_{1, j}(1 \leq j \leq P)$. We can go back to the second step, and repeat the process until the $g$-th generation has a model $\mathbf{m}_{g, j}$ such that $\Phi\left(\mathbf{m}_{g, J}\right)$ is sufficiently close to one, or until $g$ reaches the maximum number of generations $N G$.

We combine the genetic with the linearized inversion methods, generating a hybrid (GA-LI) algorithm (PORSANI et al., 1993). As shown in Figure 8, the hybrid algorithm starts with an initial ensemble of randomly selected 2D resistivity models. Synthetic 2D VES corresponding to each model are computed and compared with the data to generate the fitness function for each model. The fitness functions from the current generation are compared to those from the previous generation and kept subject to an update probability. We next find the best model in each generation and apply the $\mathrm{LI}$ method. At the end of each $G A$ iteration, we set

$$
\mathbf{m}_{0}=m_{g, J}, \quad \Phi\left(\mathbf{m}_{g, J}\right)=\max \left\{\Phi\left(\mathbf{m}_{g, j}\right), \quad 1 \leq j \leq P\right\},
$$

apply the iterative method (14) to $\mathbf{m}_{0^{\prime}}$ and if the resulting model $\mathbf{m}_{k}$ satisfies $\Phi\left(\mathbf{m}_{k}\right)>\Phi\left(\mathbf{m}_{g, J}\right)$, it is accepted into the population re-

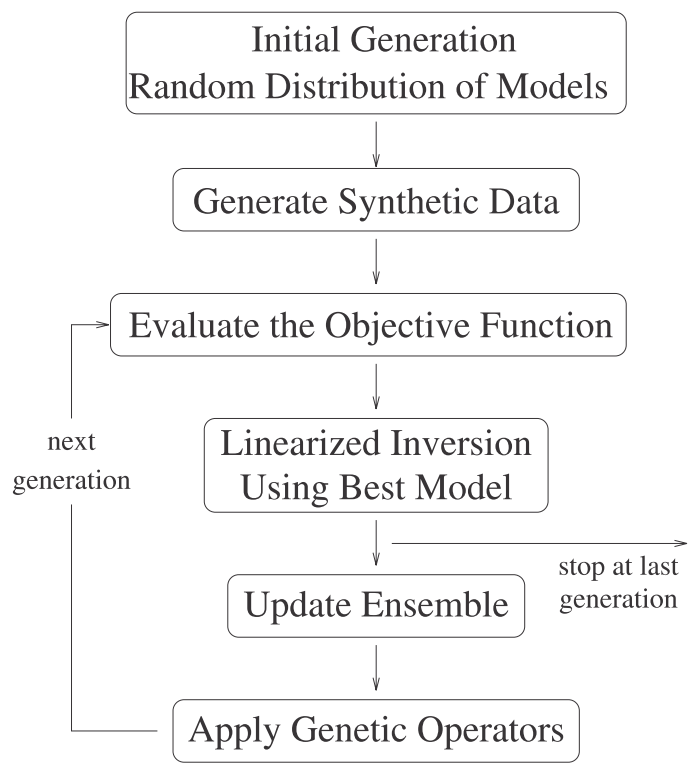

Figure 8 - Flow chart for the combined GA and LI algorithm. Figura 8 - Fluxograma do algoritmo GA combinado com LI. 
placing $\mathbf{m}_{0}$. The algorithm then proceeds as in AG. The genetic operators of selection, crossover and mutation are applied to the models to provide the next generation of $2 \mathrm{D}$ resistivity models for evaluation.

\section{INVERSION OF FIELD DATA}

This section illustrates the improvement of the hybrid approach over genetic algorithms. We consider the same settings as in the experiment with linearized algorithms.

The probabilities associated with the genetic algorithm are set similarly to earlier cases (CHUNDURU et al., 1995; SEN; STOFFA, 1995): $P_{c}=0.6, P_{m}=0.01$ and $P_{u}=0.95$. The resolution of the free parameters is shown in Table 2. Moreover, $T_{0}=5$ and $\gamma=0.98$.

Both algorithms employ 200 generations with a fixed population of 250 models. The hybrid algorithm performs ten iterations of the linearized inversion algorithm, under the $L_{2}$ norm. Notice that the hybrid approach led to a considerable decay of the relative error (Figure 9). The best models of genetic and hybrid algorithms are shown in Figure 10.

Table 2 - Parameters that define the resolution of each model component for the experiment with field data according to equation (18).

Tabela 2 - Parâmetros que definem a resolução de cada componente do modelo para o experimento com dados de campo, de acordo com equação (18).

\begin{tabular}{|c|c|c|c|c|}
\hline Layer & Blocks & $m_{i \text { imin }}(\Omega m)$ & $m_{i \text { max }}(\Omega m)$ & $\Delta m_{i}(\Omega m)$ \\
\hline 1 & All & 5 & 80 & 5 \\
\hline $2-3$ & Left of S15 & 5 & 800 & 5 \\
\hline $2-3$ & Right of S15 & 200 & 2.000 & 10 \\
\hline 4 & All & 5 & 800 & 5 \\
\hline 5 & All & 250 & 800 & 10 \\
\hline
\end{tabular}

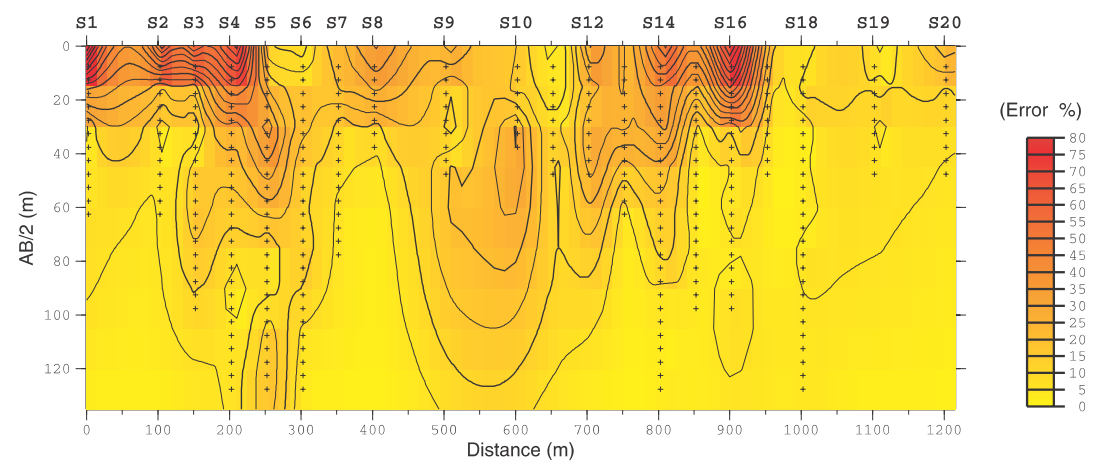

(a)

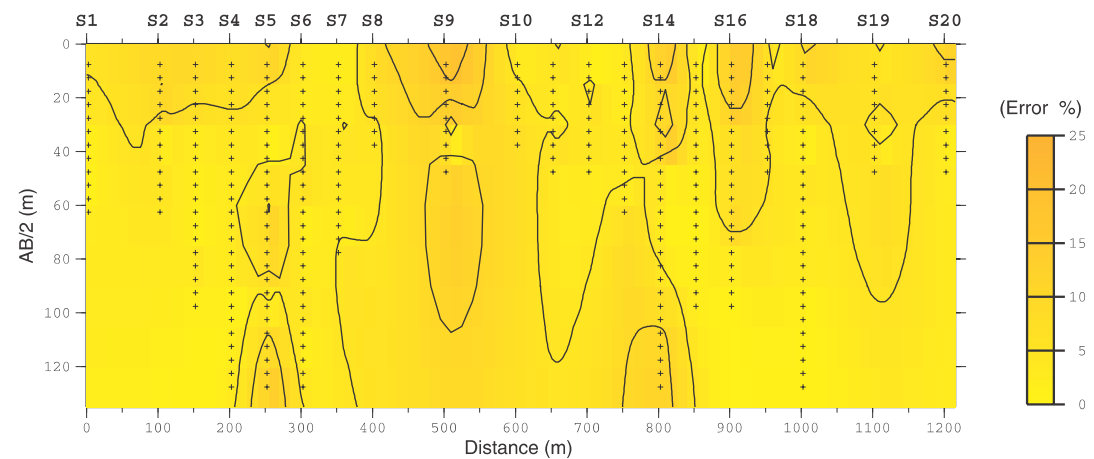

(b)

Figure 9 - Pseudo-section of percent relative error of the theoretical apparent resistivity values with respect to the observed apparent resistivity values for the genetic algorithm (a) and the hybrid GA-LI algorithm (b). Figura 9 - Pseudo-seção do erro relativo dos valores teóricos de resistividade aparente gerados pelo algoritmo genético (a) e pelo algoritmo hibrido GA-LI (b) com respeito aos valores de resistividade aparente observados. 


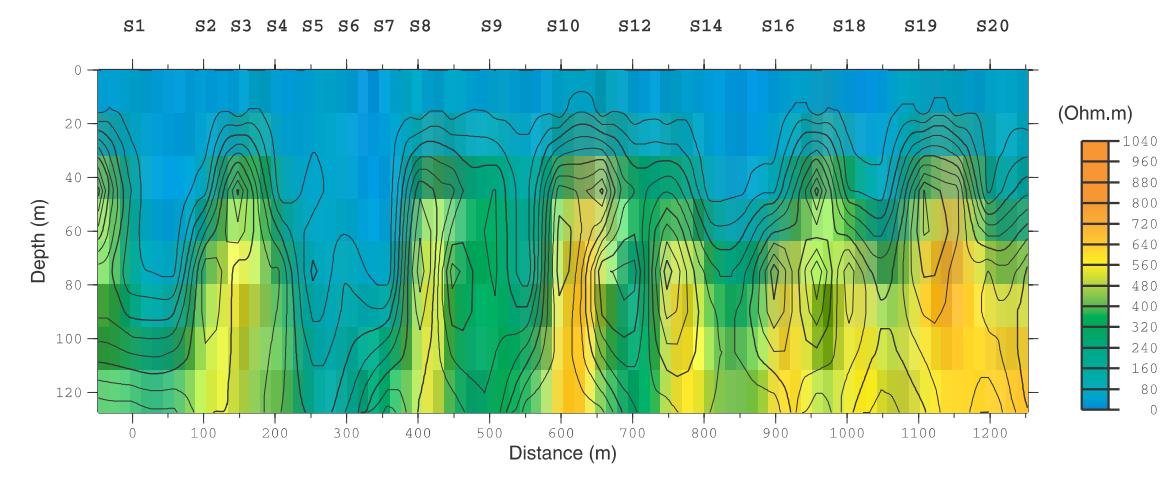

(a)

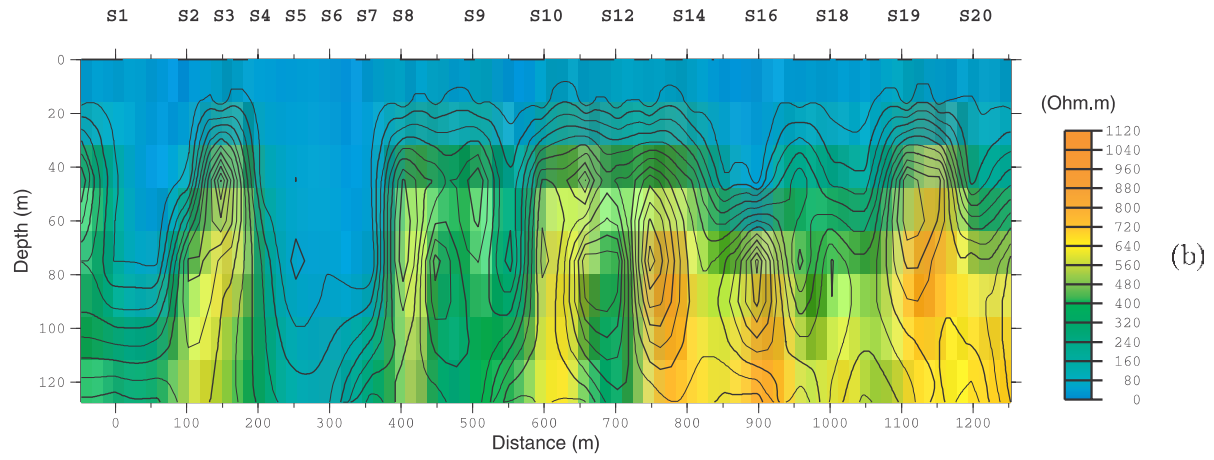

Figure 10 - Contours of the apparent resistivity values generated from the inverted models by using the genetic algorithm (a) and the hybrid GA-LI algorithm (b).

Figura 10 - Seções de valores de resistividade aparente resultantes dos modelos invertidos pelo algoritmo genético (a) e pelo algoritmo híbrido GA-LI (b).

\section{DISCUSSIONS AND CONCLUSIONS}

This article extends previous work in $1 \mathrm{D}$ resistivity inversion for 2-D inversion of sets of vertical electrical sounding. We incorporate the linearized inversion approach into a genetic algorithm. The best model, found at the end of each generation of the $G A$, was improved by using the LI method. By doing so, we found that a combined GA-LI approach performs better than a pure $\mathrm{GA}$, and better than a pure $\mathrm{LI}$ run. The hybrid algorithm was tested to simultaneously invert families of synthetic and measured VES data using a $2 \mathrm{D}$ resistivity model. The GA-LI algorithm accelerates the convergence to the global optimum.

Our experience using the hybrid GA-LI algorithm indicates that employing linearized inversion on initial steps of the GA-LI algorithm may overemphasize a local search, specially if the best models are near local optima. On the other hand, a typical GA performance curve grows faster in the first generations, which suggests that this method is efficient on identifying the neighborhood of the global optimum. The growth is slower in the following steps and tends to saturation. Therefore LI refinement is more appropriate in later steps. A key question is when linearized inversion should take place. Another question is whether hy- brid methods can be improved with more complex local search methods (for instance, multiple re-weighted least-square methods). These questions contribute to a deeper understanding of $2 D$ inversion of geophysical problems.

\section{Acknowledgements}

The authors are thankful to Dr. Vicente Pinheiro Neto for providing the set of VES data used to test the algorithm. The third author is supported by the PRODOC fellowship granted by CAPES, Brazil.

\section{REFERENCES}

ABRAMOWITZ, M.; STEGUN, I. Handbook of mathematical functions. New York: Dover, 1970.

CARY, P. W.; CHAPMAN, C. H. Automatic 1-D waveform inversion of marine seismic reflection data. Geophys. J. Int., [S.I.], v. 93, p. 527-546, 1988. CHUNDURU, R. K. et al. Non-linear inversion of resistivity profiling data for some regular geometrical bodies. Geophys. Prosp., [S.I.], v. 43, p. 979-1003, 1995. 
GERSZTENKORN, A.; BEDNARD, J. B.; LINES, L. R., 1986. Robust iterative inversion for the one-dimensional acoustic wave equation. Geophysics, [S.I.], v. 51, p. 357-368, 1986.

GOLBERG D. E. Genetic algorithms in search, optimization and machine learning. New York: Addison-Wesley, 1989.

HOLLAND, J. H. Adaptation in natural and artificial systems. Ann Arbor: University of Michigan Press, 1975.

GREENBAUM, A. Iterative methods for solving linear systems. Philadelphia: SIAM, 1997.

KOEFOED, 0. Geosounding principles 7: resistivity sounding measurements. Amsterdam: Elsevier, 1979.

LIU, P.; HARTZELL, S. A; STEPHENSON, W. Nonlinear multiparameter inversion using a hybrid global search algorithm: applications in reflection seismology. Geophys. J. Int., [S.I.], v. 122, p. 991-1000, 1995. MCGILIVRAY, P. R.; OLDENBURG, D. W. Methods forcalculating Fréchet derivatives and sensitivities for non-linear inverse problem: a comparative study. Geophys. Prosp., [S.I.], v. 38, p. 499-524, 1990.

MEDEIROS, W. E. Eletro-resistividade aplicada à hidrogeologia do cristalino: um problema de modelamento bidimensional. 1987. Dissertação (Mestrado)-Universidade Federal da Bahia, Salvador, 1987. MEIJERINK, J. A.; VAN DER VORST, H. A. An iterative solution method for linear systems of which the coefficient matrix is a symmetric M-matrix. Mathematics of Computation, [S.I.], v. 31, p. 148-162, 1977.

MENKE, W. Geophysical data analysis: discrete inverse theory. New York: Academic Press, 1989.

PINHEIRO NETO, V. Modelagem estrutural-geoelétrica de rochas cristalinas fraturadas. 2000. Tese (Doutorado)-Universidade Federal da Bahia, Salvador, 2000.

PORSANI, M. J. et al. A combined genetic and linear inversion algorithm for waveform inversion. In: ANN. INTERNAT. MTG., 63., 1993, Wash- ington, DC. Expanded Abstracts... Washington, DC: [s.n.], 1993. p. 692695.

et al. Fitness functions, genetic algorithms and hybrid optimization in seismic waveform inversion. J. Seism. Explor., [S.I.], v. 9, p. 143-164, 2000.

, NIWAS, S.; FERREIRA, N. F. Robust inversion of vertical electrical sounding data using a multiple re-weighted least square method. Geophys. Prosp., [S.I.], v. 49, p. 255-264, 2001.

RIJO, L. et al. Interpretation of apparent resistivity data from Apodi Valley, Rio Grande do Norte, Brazil. Geophysics, [S.I.], v. 42, p. $811-822$, 1977.

ROTHMAN, D. H. Nonlinear inversion, statistical mechanics and residual statics estimation. Geophysics, [S.I.], v. 50, p. 2784-2796, 1985.

SCALES, J. A.; GERSZTENKORN A. Robust methods in inverse theory. Inverse Problems, [S.I.], v. 4, p. 1071-1091, 1988.

SEN, M. K.; BHATTACHARYA, B. B.; STOFFA, P. L. Nonlinear inversion of resistivity sounding data. Geophysics, [S.I.], v. 58, p. 496-507, 1993.

; STOFFA, P. L. Global optimization methods in geophysical inversion. Amsterdam: Elsevier, 1995.

STOFFA, P. L.; SEN, M. K. Nonlinear multiparameter optimization using genetic algorithms: inversion of plane-wave seismograms. Geophysics, [S.I.], v. 56, p. 1794-1810, 1991.

TARANTOLA, A.; VALETTE, B. Inverse problems-quest for information. J. Geophys., [S.I.], v. 50, p. 159-170, 1982.

ZHANG, J.; MACKIE, R. L.; MADDEN, T. R. 3-D resistivity forward modeling and inversion using conjugate gradients. Geophysics, [S.I.], v. 60, p. 1313-1325, 1995. 


\section{NOTAS SOBRE OS AUTORES}

Niraldo Roberto Ferreira é graduado em Engenharia Elétrica na Universidade Federal de Pernambuco em 1977. Mestrado em Geofísica pela Universidade Federal da Bahia, 1994. Doutorado em Geofísica pela Universidade Federal da Bahia, 1999. Atualmente professor da Escola Politécnica da UFBA.

Milton José Porsani é B. C. em Geologia pela USP, 1976. Licenciado em Geologia pela Faculdade de Educação da USP, 1977. Mestre em Geofísica pela UFPA, 1981. Doutor em Geofísica pela UFBA, 1986. Pós-doutorado em Geofísica, Institute for Geophysics at University of Texas at Austin, EUA, setembro/92 a outubro/93. De 1986 até o presente é Pesquisador do CPGG/UFBA onde coordena o Programa de Exploração de Petróleo. Em 1990 foi contratado pela UFBA mediante concurso público para professor do Departamento de Geologia e Geofísica Aplicada do IGE0. Desde 2000 é professor Titular na matéria Exploração de Petróleo. Pesquisador do CNPq, nível I-B. Tem atuado no desenvolvimento de métodos e algoritmos de filtragem e processamento de dados sísmicos e na inversão de dados sísmicos e elétricos.

Saulo Pomponet de Oliveira é graduado em Matemática Aplicada e Computacional pela Universidade Estadual de Campinas, Campinas, SP, em 1997. Mestrado em Matemática Aplicada, Universidade Estatual de Campinas, Campinas, SP, em 1998. Doutorado em Matemática Aplicada, University of Colorado, Denver, Estados Unidos, em 2003. Atualmente bolsista recém-doutor (PRODOC-CAPES) do programa de pós-graduação em geofísica da Universidade Federal da Bahia. 